\title{
Parental Uncertainty as Pain: A Reading of Dr. Spock ${ }^{1}$
}

\author{
Stanley Raffel \\ University of Edinburgh
}

\section{The Expression and Representation of Pain}

What is a mature relation to pain? Perhaps we can begin to answer by considering a baby's reaction to pain. When a baby is in pain, it cries. The cry expresses a need with respect to the pain, a need for the pain to stop. More than the cry being to stop the pain, the cry is stop the pain. The cry is a scream. The cry does not seek to formulate the pain or to represent the pain as pain. We might say that the cry expresses the pain: as a speech it is an immature form of discourse insofar as it is self-expressive rather than self-representational.

The baby does not have the notion of pain though he expresses pain to one who has. In Hegel's terms, the baby is not "subject" to the concept (of pain) and master of its use; he does not orient to pain as pain. That he expresses pain means that he is oriented to being in pain. We want to say that one of the things that the adult feels for the baby is sympathy (sentimentality) for this very inability to orient to pain. Isn't the adult's pain over the baby's lack of qualification sentimental if the baby is by nature unqualified?

There is some possibility of the following analogy here: Just as the baby needs the pain to stop, the parents need the cry to stop. The baby's cry is the parents' pain. A question which then arises is whether the parents should respond to their pain (the baby's cry) in the same way as the baby responds to his pain, by crying? If they do, they would seem to be treating themselves as if they were babies. One question we might ask is how the parents should respond to their pain if they are to be mature (to do something other than cry)?

Another way of saying this is to suggest that the parent's pain is caused by the baby's cry and so the parent is to treat the baby's cry as painful and yet not immaturely. An immature treatment of the pain (treatment of the cry) would merely be expressive as if the parents would cry. Instead, a mature parent tries to understand the cry-its source or cause-and so to represent his pain as pain.

If we say that the mature relation to pain (e.g., the parent's relation) is self-representational rather than self-expressive we mean that the parent acts upon his pain rather than expresses it. To grasp this distinction, imagine a parental version of expressing pain — of crying - and we glimpse an immature relation to pain. In contrast, self-representation implies that pain - or any relation to conditions - must be deliberated or mediated.

Babies must have different needs than parents and we can begin to approach this difference by considering what the baby needs when it cries. Simply, it needs the pain to be removed. If a safety pin is stuck somewhere, we remove it. If there are hunger pains, we feed the baby. In general, what we are seeking to give the baby could be formulated as comfort. Comfort treats pain as something to be removed so as to return the body to its normal, usual, easy state. Now to be comforting seems the right way to treat a 
baby, who can have no sense of what a pain might mean. Comforting is what the immature or unqualified relationship (to pain) elicits but is not what the mature or qualified relationship elicits. For example, if the parent experiences pain at the sound of the baby's cry we do not comfort him but help him represent the pain as a condition so as to understand how to act upon it. ${ }^{2}$

That the baby cannot orient to what it expresses is what it means to be unqualified. On the other hand we are qualified and one of the things we know is that the unqualified need to be comforted whereas we do not have to be comforted in knowing this. Our knowledge of the difference between qualified and unqualified does not give us pain or require comfort. Perhaps what we need is advice.

\section{The Pain of Parental Discomfort}

What is problematic about Dr. Benjamin Spock's famous book, Baby and Child Care, is that a close reading raises the possibility that he may be treating parents by comforting them:

A parent usually feels guilty the first time this (an accident) happens. But if a child is so carefully watched that he never has an accident, he is being fussed over too much. Bones may be saved, but his character will be ruined. (Spock, 1968, p. 537)

One is struck, not just here but throughout the book, with a sense that Spock's statement is true. Yet his point is not so much true in any telling sense as it is obvious. Maybe it seems truer than it really is because it softpedals the issue. Thus, when a single accident occurs, why isn't the real issue the need to make them less frequent? In telling parents whose child has just had an accident that if he never has one, his character will be ruined, Spock seems to be trying to get them to feel good about the accident, almost to make it seem as if nothing decisive has really happened. The accident causes the parents pain (guilt) and Spock's response seems to be to seek to remove the pain by comforting the parent.

When the child has an accident, the parents feel responsible as if they were a causal agent. The one who is qualified by definition assumes responsibility for whatever happens to the unqualified. Isn't that a feature of being depended upon - that you can always be held accountable for whatever happens to the unqualified? But, if the parent understands the essential nature of this relationship he understands that he is continuously accountable. And so, we might begin to understand the adult's pain for the pain of his child as his regret that he has not done as he should for one who depends upon him. The parental relation to pain can coexist as a guilty and sentimental lament for one's failure as a parent.

Spock seems to begin by conceiving of the parent as one who requires comfort because of his guilt for the pain of the child. That is, the parent's pain is not based on empathy for the experience of the child as if he identifies with the child for that would be abstract in the absence of an equal relationship between their particularities.

Additional examples further document Spock's orientation toward comforting: 
Most wounds bleed a little for a few minutes, and this is good because it washes out some of the germs that were introduced. (Spock, p. 531)

Blood, which causes the parents pain, is formulated as good in order to help the parent to avoid experiencing the pain he would normally experience at the sight of blood.

So if your child around 2 or 3 has a convulsion at the onset of a fever, it doesn't necessarily mean that he has a serious disease, and it doesn't mean that he is going to have more convulsions in later life. (Spock, p. 528)

Needless to say, every chronic convulsive must have a first one so again Spock is not so much telling us the absolute truth as he is using banality or homily as a way of removing the unease (pain) we would experience when the child has a convulsion.

Instead of multiplying examples, let us begin to consider the point of Dr. Spock's "treatment" of adults (readers, including us). First, he is treating us rather than the baby. There would seem to be nothing wrong with this except that he seems to be treating us as if we were babies. Perhaps there is some important recognition here of what it is like to have a baby: that it is to be open to pain. This means that we too (like babies) feel pain. Spock is frank with us in at least the sense that he lets us see that we and babies experience pain. The difference between us and babies is certainly not that they experience pain and we do not. Spock begins his book with the important acknowledgement that the baby can cause us pain:

Soon you're going to have a baby ... You're happy and excited, but if you haven't had much experience, you wonder whether you are going to know how to do a good job. (Spock, p. 3)

While acknowledging our happiness and excitement, what Spock emphasizes is our wonder. Wonder here is equivalent to worry. Our happiness is punctuated with worry, with a kind of unhappiness. Our excitement is also nervousness. ${ }^{3}$ Spock, then, does not treat the baby as sheer blessing. He is not just writing a greeting card. He begins by accepting our pain about the baby.

But, does anyone think that adults do not feel pain? Some insist: "Big boys don't cry" by which they mean that big boys do not show that they are in pain. Though they may feel pain, they do not permit it to influence or effect them and so they are invulnerable to it. If learning this sort of control over pain is learning to be hard, Spock is soft. Instead of denying our pain by not showing it, Spock encourages us to show it. He lets us show it and then comforts us. The problem this treatment raises is that if hardness makes no place for the baby except as what we outgrow, Spock seems to treat us all as if we were babies in that his response to our pain seems the same as his response to the baby's pain: He comforts us; he eases us; he seeks to remove our pain.

\section{Softness and Hardness}

Spock's softness consists of his instruction to us to comfort ourselves when we are in pain (and to comfort the other when he is in pain). That Spock tries to comfort us just as he tells us to comfort the baby shows how he treats us as he would treat the baby-as immature. In no case does 
Spock urge upon us the hardness that would deny the pain in self or ignore the pain in other.

For a good example of what we speak of as hardness note this statement from Russell:

For example: when you want a child to sleep, do not wheel it upward or down, or take it in your arms, or even stay where it can see you. If you do this once, in an incredibly short space of time it becomes a terrific business to get the child to sleep. Make it warm and dry and comfortable, put it down firmly, and after a few quiet remarks leave it to itself. It may cry for a few minutes, but unless it is ill, it will soon stop. (Russell, 1948)

Russell is suggesting that it is important to resist the child's demands in order to do what is right. Thus, to be an exemplary parent requires a certain degree of character or hardness associated with resisting the natural impulse to indulge and comfort the cry. We gather then that the parent's natural tendency is to give to his offspring and that the child's natural response is to stimulate this giving in order to get more. Russell implores the parent not to indulge the child's every want by learning to distinguish what he might call a good or real cry from a bad cry. According to Russell, the hard parent should be suspicious of all crying under the auspices of his concern to discriminate crying animated by real needs from crying animated by spurious needs or self-expression.

What seems to be required of a good response to pain is to preserve both impulses of softness and hardness: that our pain is vivid and real and that we need to take hold of our self and act upon it. Dr. Spock seems to think we will stop crying only if we are soft (if there is no pain, only when we are comfortable, only when we treat ourselves like babies). In contrast, those who recommend hardness think we can simply reject the pain which is to deny and externalize the dependency and vulnerability of our conditional existence. Softness indulges our dependency while hardness denies it. The topic of pain thus raises the question of a moderate relation to conditions that resist the extremes of softness or hardness.

\section{Accountability as Discomfort}

Essentially we are saying that we need advice in order to orient to the difference between the unqualified and the qualified since that difference suggests that we are continuously accountable. It is our continuous accountability that must be oriented to as a condition of being a parent.

We have discussed the possibilities of two types of advice. We have called them comfort and hardness. Comfort recognizes our guilt as grief but it is not. In other words we have not lost anything with our accountability and the recognition it generates of the child's unqualifiedness. When we act with self-pity, by mourning or with melancholy as if our effects are decisive we are only sentimental over our being depended upon.

What such dependency suggests instead is that we require the assistance of conversation. This conception of needing to be comforted over the decisiveness of our leadership as parents reflects the medical interest which treats everything as life and death, i.e., as survival. Spock's continuous comforting denies our need for conversation, glosses this need by looking on the bright side. We require a response that addresses the fact rather 
than our feelings. In contrast Russell's conception of hardness gives us the facts in response to medicine, e.g., it lays out our options and the consequences of various actions. Russell says if this is done, such-and-such will follow. Instead of sentimentally comforting us and encouraging our selfpity Russell inventories the possibilities. Yet he orients to the tyrant's fear of being disliked, of being out of favour with those whom you lead. Russell's conception of hardness presupposes the fate of the tyrant as risking affection and continuously orienting to being manipulated. For him being depended upon produces hatred in the dependent and so Russell treats the relation between affection and leadership politically. The difference then between Spock and Russell is a difference between comfort and hardness as the difference between medical and political relations to pain and accountability. It is important to be confident that you are doing the right thing in order to resist the child. Hardness depends upon our ability to anticipate consequences with security. Actually this is comfort, too, for it points to a corpus for justifying and fortifying our actions.

Pity laments one's humanity, it regrets one's inability to rule the conditions. The suspiciousness of hardness also reflects the fear that one's existence is conditional and therefore that one is unable to control one's self in such a way as to be free of all conditions. In this sense hardness does not want to be taken advantage of and we see the possibility of two relationships to the weak or to those who are subjugated: the relationship of lament and pity and the relationship which seeks to resist out of the fear of being manipulated or replaced. Consequently hardness is Machiavellian in the worst sense insofar as it always expects the worst of the other and so is always hard on the notion of childhood and in particular on the child.

The relation to the child with its essential character of ambiguity and uncertainty then reflects the relation between speech and language, i.e., the figurativeness of man's relationship to the whole. The situation with the child reflects the adult's inability to be certain as a consequence of his not being able to depend upon the child to make himself intelligible and interpretable. But, if the child could make himself intelligible he would not be the child.

Earlier we introduced the distinction between a self-expressive and self-representational approach to pain (conditionality). Both the comfort of softness and the denial which is hardness are self-expressive because as courses of action they do no more than express how they are in the grip of conditions. ${ }^{4}$ Softness and hardness might alternatively placate or ignore the pain they could experience, but in doing either they orient to the pain as a disturbance which is external or incidental to what they are. This is to say that self-expression cannot imagine expressing itself completely without either qualifying or ignoring the conditional. It does not see the need to represent the conditional as a problem for action. This is what Sartre means when he says that an authentic relation to condition must act as if it is chosen: we must act to make our relations to conditions choice-worthy. ${ }^{5}$

We do not choose to be in pain: pain inhabits our bodies as a condition to which we must be responsive. To make our relationship to the condition of pain choice-worthy or worthy of choice is not to choose pain (which would be masochism) but to make out of our relationship to pain a relation 
that is exemplary of choice. Self-representation represents our relationship to the condition in the best way it can imagine whereas self-expression only expresses the fact that it is in pain. Self-representation does not merely represent pain for that would only be to recapitulate the condition as self-expression; it aspires to represent a standard to emulate in establishing an authentic relationship to pain. In contrast to self-expression and its forms of softness and hardness, self-representation always requires a relation to conditions that is truly composed and neither indulgent nor ascetic.

To make a relationship to conditions choice-worthy is to liberate the relationship from its oppressive character. This means that we must transform it from a condition that determines to a condition that limits. Selfrepresentation represents one's relation to conditions so that it can be enjoyed and worked upon.

\section{Pain and Discourse}

If our relations to pain impersonate types of discourse, we understand the immature (childlike) and the mature (parental) relations to pain as two alternative discursive possibilities raised by the problem. Concretely, the immature cry when they are in pain (self-expression) and the mature seek to act upon the pain (self-representation). In our example, if the baby's cry expresses his pain, the parent's reaction to the pain of the baby's cry for him life) should be to act upon that pain rather than to recapitulate an adult version of the cry. Thus, we are saying that the immature relation to pain asks for comfort, whereas the mature relation to pain resists comfort as an end, asking instead for guidance and instruction.

It is apparent now that our talk of pain, babies, adults and the like, is a way of raising the problem of how discourse needs to be responsive to conditions. Pain as a condition-apparently incorrigible in its presence-controls our response; the immature merely express the fact that they are in pain (they howl, they wail), for like Sartre's inauthentic Jew they choose to be determined by conditions; the mature represent their pain as a condition to be acted upon, i.e., like Sartre's authentic Jew, they choose what they are-Jewish-by working to make it exemplary or worthy of choice.

Spock then raises the concern for us of whether comfort does not say to those in pain that self-expression is enough and so whether it does not distract them from the action of self-representation (of doing the work needed to make their relation to conditions worthy of choice). We suggest that while comfort is a natural and instinctive response to pain, it tends to recapitulate the very same self-expressiveness of the cry it comforts; this is because comfort expresses the pain of the comforter. What we need to imagine is a self-representational and mature response to pain which is something other than comfort and which takes form as a teacherly interest in pain. Do we not envisage here something other than philanthropy, pity or altruism as a response that could be both humane and morally oriented and yet which would resist comforting in its concern with pain?

Hardness and softness typify then, two immature relations to pain insofar as they each exemplify a self-expressive relationship. In both its cry 
and its attempt to endure the cry, the soft response to pain seeks to comfort and so to deny the experience of pain as something from which it can learn. So for example, softness is shown in the advice that pain will run its course or that it will end or that something good will come out of it. Softness is akin to the good-heartedness which comes to mind in discourse, when we think of it as placating, when one's particular condition of pain is qualified through its assimilation to that which is universal.

If the baby's cry gives the parent pain, Spock encourages the parent to think of that pain in a way which will make it endurable, e.g., by thinking of how it will end or how it is good for character formation. What placating expresses is the need to make our relationship to conditions comfortable and so it resists the tension that inevitably occurs when we find ourselves inarticulate or hesitant in a situation of action. Yet it is the productiveness of this tension which we utilize as we move to compose ourselves with respect to what we must do. If softness agrees that pain is inevitable it suggests comfort and placating as the only ways of enduring the inevitable. Hardness refuses to grant pain a life of its own by inviting us to treat it as an expression of dependency-a weakness-that can be mastered. Hardness says that to be in pain is to be overcome by conditions in that one has failed to govern the relation of self to conditions in a way that exhibits composure rather than dispersion.

Because being in pain is seen as a result of a miscalculation (the pain can always be denied) hardness urges us to will composure and hence the irrelevance of pain. Hardness expresses the need of the organism to exhibit mastery - to be in control-and to be uninfluenced by the dependency of pain. We might say that hardness is idealistic in that it denies or distorts the fact of pain (of condition, of nature) in the service of its willful idealization of uninfluenceable self control and composure as its goal. If hardness' denial that it can be influenced stands to softness' qualification of that by which it is influenced as two forms of the immature or self-expressive relationship to pain, we can say that they both deny pain (nature) in the service of self-assertion and of the need to establish a comfortable relationship to conditions. Both hardness and softness gloss the experience of pain as an inevitable and incorrigible condition of life.

The question then is, what is the status of such a gloss and how can its temptation be resisted?

\section{The Hurt of Finitude}

We have suggested that pain-our conditionality-must be experienced as an essential part of our life and not glossed. Concretely, our conditionality refers to our being limited; so we need to experience and not gloss our limit. ${ }^{7}$ How does our limit show itself in our relation to pain? In our example, the parent's pain is a feature of his self-consciousness, of his subjectivity vis-à-vis language; the child's pain is a feature of his ignorance or his not knowing what is happening to him. The parent's relationship to this difference should be mature, i.e., it is this difference which is a condition to which the parent must orient.

What appears to cause us pain is the fact that we cannot reduce the pain of the baby whereas what causes the baby pain is, e.g., an illness. We 
are in pain by virtue of our understanding of our self and our limits; we are in pain because we are depended upon and in our turn, dependent upon what is beyond our powers. If the baby is dependent or helpless that is not why he is in pain: dependency can only be painful for a mature consciousness, a fully formed social actor. The baby's dependence upon the parent is painful for our parent because he must depend upon resources he does not have. What is painful to the parent in the fact of his being depended upon is that it shows how he (the parent, the human) is essentially a dependent being. In the baby's dependence upon him the parent again experiences his own essential dependency. Yet, if the pain of that experience needs to be recognized for what it is and not glossed it must be transformed into an understanding that is enjoyable and not oppressive. This is because in our life the baby is one who does not know what is happening to him and so the dependency of the unqualified becomes painful in itself.

Now we can venture: if the baby's pain is caused by his body, the parent's pain is caused when he understands the body as a determinant which controls him by virtue of it making his dependency oppressive rather than enjoyable; the parent must begin to understand the body as a condition rather than as a determinant. As a very tentative beginning toward a formulation of an adult relation to pain, contrast a baby's and an adult's reaction to a pin prick. Insofar as the baby can feel it, it screams in pain. The adult, by contrast, would say something, for example, "Oh, that hurts." We are not just noticing that adults can speak while babies cannot but that for the baby, the pain has no locale. The baby is the pain and so it screams whereas the adult has the pain. For the adult, the pain has a place or location. The location is somewhere on or in the body so we can say that what the pain affects is the body. What the adult's "Oh that hurts" shows, then, is that being an adult involves having a relationship to one's body whereas being a baby amounts to being a body.

A mature relationship to pain now seems to involve having a relationship to one's body. How could we see softness and hardness in these terms? Hardness would seek to strengthen our bodies, to make them invulnerable to pain. Dr. Spock's idea is to comfort which would seem to soften our bodies. His alternative to making us invulnerable to pain seems to be to make us insensitive to pain, to numb our bodies, as it were. With regard to our bodies, a more exact formulation of comfort, then, is that instead of seeking to remove the pain, it eases it. It tries to make our bodies relatively numb to the pain. Thus:

Think of breast feeding simply as a good thing if you really enjoy it and it works, but no cause for despair if not. (Spock, p. 76)

He needs a cheerful mother more than he needs breast milk. ${ }^{8}$

Despair amounts to crying, so Spock's notion seems to be that those who cannot breast feed would feel a pain that would make them cry and he numbs them to the pain by saying that if they can't enjoy it, it isn't good for them. The stronger point might be that if they can't enjoy what is good (for the baby) there is something wrong with them. This sort of recognition could be their pain. Spock is easing this rather than trying to make something out of it. He doesn't make an issue of it. ${ }^{9}$

Worry only discourages milk supply. (Spock, p. 85) 
The main trouble with bottle feeding ... is that the mother can see how much formula is left. (Spock, p. 123)

In both cases, Spock thinks that by easing the pain (over low milk or low appetite) things will be better. What the mother could do (worry, see) would only make matters worse. The mother has to be numb because otherwise her pain (now worry) will only make matters worse. ${ }^{10}$ Making the body numb is making the pain have no meaning. We are comfortable insofar as we do not experience the pain. Hardness makes us so strong that the pain will not affect us. Softness makes us so weak that the pain will not worry us. We will not even feel it in the sense that we have no sensitivity to its meaning. Dr. Spock seems to want to protect us from the pain, from its meaning, whereas hardness wants each of us to protect ourselves. In both cases, possibilities for experiencing the pain are not really considered. Hardness tries to get our bodies to protect us, as if they are shells. Spock pads and protects us. In contrast to both, aren't our bodies made to experience pain? Isn't that what they are good at, what they are for?

But this point itself sounds hard. That our bodies are made for pain sounds as if our life is made for suffering. In contrast, Spock is an optimist, with a "positive" view toward life:

Urging destroys some of his positive feeling for life. (Spock, p. 124)

The baby should not be urged because the pain he would experience in being pushed might begin to convince him that life is bad. The danger in pain is that if we have too much of it we will begin to hate life. Pain is the hateful side of life and so it must not be.

\section{The Enjoyment of Finitude}

The cry of the baby appears to raise two possibilities for the parent. On the one hand, there is the helplessness of the baby reflected in his mere capacity to express the fact that he is in pain. The parent does not want to recapitulate the baby's response in that sense; he needs to do more than express the fact that the dependence of the baby gives him pain. Yet, the dependence of the baby is painful since it raises for the parent his sense of limit and of what he cannot do. In his way, the parent appears to himself just as helpless as the baby in the face of pain-in the face of his conditionality, of his limit. On the other hand, if we say that the parent can theorize, we mean that he can formulate and orient to the problem of his limitation. It is the adult who knows that he must act despite and in the face of his dependency. If the baby's dependence upon the parent is to be an enjoyable rather than oppressive condition for the parent, then the latter must take action in the face of the discomfort which he experiences in the recognition he achieves of his very own dependency.

Discomfort takes form in the adult's need to embody Desire in discourse in the face of his recognition of his essential dependence. That is, the dependence of the baby upon the parent who himself is essentially dependent means that the parent must take authority knowing that its exercise is both necessary and desireable and essentially equivocal. What the parent knows, then, is how the social actor is essentially limited by virtue of 
the condition that the unequivocal need to take action always co-exists as a feature of the action's equivocality. The social actor's knowledge that Desire must be embodied implies that he knows that his wants, values and needs have to be enacted in discourse.

Thus we might say that the quintessential condition by which the social actor is confronted is the condition of embodiment, of needing to enact Desire in the practice(s) of speaking. He must establish an authentic relation posed by his understanding of how he needs the bodyembodiment-and of its limits. In terms of the example used in this paper, we need to experience embodiment enjoyably rather than be its victim: this is to require of ourselves to resist the temptations of softness or hardness in conceiving of our dependence as speakers by taking discursive authority in action even insofar as the limitation of our authority is conceded and enjoyed.

\section{Notes}

1. This paper was written at York University and developed out of participation in the project on the Problem of Self-Reflection and the Study of Children's Culture.

2. For example, see Socrates' remark on how the tragic poets stimulate and appeal to the emotions in creating a self-expressive relation to pain in The Republic, (Cornford translation, X, 603, Chapter XXXVI, p. 336). Instead of crying, says Socrates, "like a child who goes on shrieking after a fall and hugging the wounded part, we should accustom the mind to set itself at once to raise up the fallen and cure the hurt, banishing lamentation with a healing touch."

3. Even here he lets us off the hook by suggesting that we are worried only because we lack experience. Wouldn't veteran parents worry about the possibility that they would be jaded?

4. A self-expressive relation to pain expresses the fact that we are in pain as an actuality without respect to that which makes it possible as such a fact. See M. Heidegger, The End of Philosophy (New York: Harper and Row, 1973) for the distinction between the thatness or actuality of a thing which says of a thing (e.g., pain) only that it is, and the whatness or essence of a thing which addresses what it must be to exist in the way it does. See also, A. Blum and P. McHugh, Self-Reflection in the Arts and Sciences (Atlantic Highlands, New Jersey: The Humanities Press, 1984).

5. See Sartre, p. 136. "Jewish authenticity consists in choosing oneself as Jew-that is, in realizing one's Jewish condition." In contrast, on page 92, an inauthentic relation to the condition of being Jewish can be seen in those who "deal with their situation by running away from it: they have chosen to deny it, or to deny their responsibilities, or to deny their isolation, which appears intolerable to them."

6. See Hannah Arendt's comments on pity, e.g., "The depth of this problem (good and evil) could hardly be sounded by those who mistook for goodness the natural innate repugnance of man to see his fellow creatures suffer." On Revolution (London: Faber \& Faber, 1963, p. 76).

7. Both Rousseau, Emile (London: J. M. Dent \& Sons, Ltd., 1974) and Durkheim, Moral Education (Glencoe: Free Press, 1961) develop strong arguments for the need to experience limitation as enjoyable rather than as privation.

8. Spock. Wouldn't it be more accurate to say he needs both? 
9. "Not making an issue" is a frequent recommendation of his.

10. Spock often refers to the process that can occur at this point as "sort of a vicious circle." Interestingly, even this message is softened with the "sort of."

\section{References}

Russell, B. (1948). On education. London: G. Allen \& Unwin.

Spock, B. (1968). Baby and child care, New Revised Edition. New York: Pocket Books. 